\title{
A Prospective Observational Study of Clinicopathological and Biochemical Profile of Patients with Cholecystitis Visiting a Teaching Tertiary Care Centre of Haryana
}

\author{
Pushpendra Malik ${ }^{1, \odot}$ Tarun L.N.U. ${ }^{2} \quad$ Sanjeet Singh \\ Rahul Kumar $^{1}$ Sebin Sebastian ${ }^{1}$ \\ ${ }^{1}$ Department of General Surgery, Bhagat Phool Singh Government \\ Medical College, Khanpur Kalan, Haryana, India \\ 2Department of General Medicine, Bhagat Phool Singh Government \\ Medical College, Khanpur Kalan, Haryana, India \\ ${ }^{3}$ Department of SPM, Bhagat Phool Singh Government Medical \\ College, Khanpur Kalan, Haryana, India
}

Mahinder K Garg ${ }^{1}$ Mukesh Sangwan ${ }^{1}$

Int J Recent Surg Med Sci 2021;7:72-76.

\section{Abstract}

\section{Keywords}

- Gallstone diseases

- clinicopathological profile

- biochemical profile

- cholecystitis
Introduction Gallstone diseases constitute a major part of patients visiting hospitals, and more than $50 \%$ of operation theaters are occupied by it or diseases related to it. It also imposes significant financial burden on health resources. The $21 \mathrm{st}$ century has opened with an improved foundation to our understanding of the basis of bile formation by defining the key transporters of the lipids in bile and the responsible genes. The specter of obesity as an epidemic in developed countries, and the recent recognition of the metabolic syndromes and their links to gallstone formation, emphasize the expectation of a rise in the frequency of cholesterol cholelithiasis.

Materials and Methods Data pertaining to patients who were admitted/received surgery for a diagnosis of gallstone diseases at the Department of General Surgery of BPS GMC Khanpur Kalan was collected.

The collected data was entered in a Microsoft Excel spreadsheet. Mean \pm standard deviation (SD) was calculated for quantitative data, using Student's "t" test/Kruskal test. Chi-square test was used to find out the association for categorical data.

Results and Discussion Most of the patients were experiencing right hypochondriac pain $(79.23 \%)$ as presenting complaints, with the most common age range being 31 to 40 years, followed by 41 to 50 years, that is, $31.85 \%$ and $20.74 \%$, respectively. Females were most commonly affected, approximately $90 \%$, and only $10 \%$ of patients with gallstones visiting our hospital were males. Maximum patients had chronic cholecystitis (80\%) on histopathological examination, followed by cholesterosis (6.15\%). As much as $82.6 \%$ of patients presented with mixed gallstones, followed by cholesterol stones, that is, $10.43 \%$. All types of stones are more common in patients with abdominal adiposities, that is, having waist-to-hip ratio more than 0.85 , and these findings are statistically significant.

Conclusion Our study concluded that gallstones were more common in females of younger population (31-40 years) with right hypochondriac pain as presenting complaints. The most common histopathology was chronic cholecystitis with mixed types of stones, which is associated with increased waist-to-hip ratio. All biochemical markers were within normal range. published online

June 16, 2021
DoI https://doi.org/

$10.1055 / \mathrm{s}-0041-1731114$ ISSN 2455-7420 (c) 2021. Medical and Surgical Update Society.

This is an open access article published by Thieme under the terms of the Creative Commons Attribution-NonDerivative-NonCommercial-License, permitting copying and reproduction so long as the original work is given appropriate credit. Contents may not be used for commercial purposes, or adapted, remixed, transformed or built upon. (https://creativecommons.org/licenses/by-nc-nd/4.0/).

Thieme Medical and Scientific Publishers Pvt. Ltd. A-12, 2nd Floor, Sector 2, Noida-201301 UP, India 


\section{Introduction}

A Greek physician, Alexander Trallianus, first described gallstones in the fifth century, and they continue to be a major health problem in today's world. Gallstone diseases constitute a major chunk of patients visiting our outdoor patient department, and they also form the leading cause of inpatient admission. Almost 50\% of operation theaters are occupied by patients having diseases related to gallstones. A similar trend is seen in Western countries. In fact, approximately 650000 to 700000 cholecystectomies are performed each year in the US. The frequency of hospital admission and operation has also increased in the Western countries since the 1950 s. ${ }^{1,2}$ More than $98 \%$ of all gallbladder and biliary tract disorders are in one way or another connected to cholelithiasis. Thus, the symptoms and complications related to gallstones in the US are among the costliest digestive disorders, at an estimated $\$ 6.5$ billion, exceeding the combined total for chronic liver diseases and cirrhosis ( $\$ 1.6$ billion), chronic hepatitis C ( $\$ 0.8$ billion), and even pancreatic diseases ( $\$ 2.2$ billion). ${ }^{3}$ The burden of gallstone diseases in Europe is similar to that of the US, with a median prevalence in large population surveys ranging from 5.9 to $21.9 \%{ }^{4}$ Gallstones nevertheless have become an increasing problem. In the UK, for example, the frequency of hospital admissions for gallstone diseases increased by $53 \%$ from 1989 to 1990 to 1990 to $2000 .^{5}$ This could reflect an increased incidence of cholelithiasis, an increased frequency for gallstones to become symptomatic, greater detection because of more readily available diagnostic imaging such as ultrasound, or a decrease in threshold for surgery. Further, similar unexplained variances in surgical practices are reported in countries in the Western world. ${ }^{1}$

Prevalence of gallstones in India was found to be $6.12 \%$ among the adult population. ${ }^{6}$ Gallstone prevalence has geographical variance as well as ethnic. A gallstone survey limited to railroads workers conducted in 1966, utilizing oral cholecystography, had suggested that gallbladder stones occurred seven times more commonly in north Indian workers than south Indian workers. ${ }^{7}$ This difference was attributed to the different ethnic backgrounds of workers. A similar study was carried out at All India Institute of Medical Sciences (AIIMS), New Delhi, among different colonies of Delhi, each with inhabitants belonging to a specific ethnic group. The study showed significant differences in gallstone prevalence among different ethnic groups, with the Punjabis being most affected (north Indians) and south Indians being least affected. ${ }^{8}$ There was also a variance in type of stones among different ethnic groups, with cholesterol being the predominant stone among north Indians and pigment stones being the predominant stone among south Indians. ${ }^{9}$ The diet is likely to be important, as the intake of calories, fat, and proteins affect the cholesterol saturation of bile. Some other potential risk factors for the development of gallstones are obesity, sedentary lifestyle, geriatric age groups, female gender, oral contraceptive pills, and family history of gallstones. ${ }^{10-12}$

The 21st century has opened with an improved foundation to our understanding of the basis of bile formation by defining the key transporters of the lipids in bile and the responsible genes. A genetic basis for racial differences of gallstone diseases is now possible and being uncovered. The specter of obesity as an epidemic in developed countries, and the recent recognition of the metabolic syndromes and their links to gallstone formation, emphasize the expectation of a rise in the frequency of cholesterol cholelithiasis. ${ }^{13}$

Our hospital caters to patients not only from Haryana but also from western UP. Gallstone diseases form a major health problem, as seen in our daily practice. So, we aimed to carry out an epidemiological study to determine the clinical, pathological, and biochemical profile of gallstone disease patients visiting our teaching tertiary care center.

\section{Materials and Methods}

Data pertaining to patients who were admitted/received surgery for a diagnosis of gallstone diseases at the Department of General Surgery of BPS GMC Khanpur Kalan was collected (symptomatic cholelithiasis) (January 2017 to July 2019).

\section{Statistical Methods}

Detailed history taking and clinical examination of all patients admitted with diagnosis of cholecystitis were done, and all relevant investigations along with lipid profile were sent in on a morning empty stomach. The collected data was entered in a Microsoft Excel spreadsheet. Mean \pm standard deviation (SD) was calculated for quantitative data using Student's " $t$ " test/Kruskal test. Percentage and proportion were calculated for qualitative data. Chi-square test was used to find out the association between categorical data. Sensitivity, specificity, positive predictive value, and negative predictive value were calculated using SPSS (version 20) software. $p<0.05$ was considered statistically significant.

\section{Results}

\section{Presenting Complaints}

Most of the patients were experiencing right hypochondriac pain (79.23\%) as presenting complaints (-Table $\mathbf{1}$ ).

\section{Age Distribution}

The most common age range for patients presenting to our hospital was 31 to 40 years, followed by 41 to 50 years, that is, $31.85 \%$ and $20.74 \%$, respectively (- Table 2 ).

Table 1 Patient distribution according to presenting complaints

\begin{tabular}{|l|l|l|l|}
\hline S. no. & Chief complaints & $\begin{array}{l}\text { No. of } \\
\text { patients }\end{array}$ & $\begin{array}{l}\text { Percentage } \\
\text { (\%) }\end{array}$ \\
\hline 1. & Right hypochondriac pain & 103 & $79.23 \%$ \\
\hline 2. & Dyspepsia & 14 & $10.77 \%$ \\
\hline 3. & Nausea/vomiting & 11 & $8.46 \%$ \\
\hline 4. & Fever & 1 & $0.77 \%$ \\
\hline 5. & Jaundice & 1 & $0.77 \%$ \\
\hline 6. & Total & 130 & $100 \%$ \\
\hline
\end{tabular}


Table 2 Patients distribution according to age range

\begin{tabular}{|l|l|l|l|}
\hline Sr. no. & Age range (years) & No. of patients & Percentage \\
\hline 1 & $20-30$ & 22 & $16.29 \%$ \\
\hline 2 & $31-40$ & 43 & $31.85 \%$ \\
\hline 3 & $41-50$ & 28 & $20.74 \%$ \\
\hline 4 & $51-60$ & 27 & $20 \%$ \\
\hline 5 & 60 & 18 & $13.33 \%$ \\
\hline 6 & Total & 135 & $100 \%$ \\
\hline
\end{tabular}

\section{Gender Distribution}

Females were most commonly affected, approximately 90\%, and only $10 \%$ of patients with gallstones visiting our hospital were males ( - Table $\mathbf{3}$ ).

\section{Pathological Profile}

Maximum patients had chronic cholecystitis (80\%) on histopathological examination, followed by cholesterosis $(6.15 \%)$ (-Table 4).

\section{Type of Gall Bladder Stones}

As much as $82.6 \%$ of patients present with mixed gallstones, followed by cholesterol stones, that is, $10.43 \%$ ( - Table 5).

\section{Distribution of Gall Stone According to Waist-to-Hip Ratio}

All types of stones are more common in patients with abdominal adiposities, that is, having waist-to-hip ratio

Table 3 Patient distribution according to gender

\begin{tabular}{|l|l|l|l|}
\hline Sr. no. & Gender & No. of patients & Percentage \\
\hline 1 & Male & 14 & $10.76 \%$ \\
\hline 2 & Female & 116 & $89.23 \%$ \\
\hline 3 & Transgender & 0 & 0 \\
\hline 4 & Total & 130 & \\
\hline
\end{tabular}

Table 4 Patient distribution according to histopathological examination

\begin{tabular}{|l|l|l|l|}
\hline $\begin{array}{l}\text { Sr. } \\
\text { no. }\end{array}$ & Pathological diagnosis & $\begin{array}{l}\text { No. of } \\
\text { patients }\end{array}$ & Percentage \\
\hline 1 & $\begin{array}{l}\text { Chronic cholecystitis with } \\
\text { hyalinization and calcification } \\
\text { in wall }\end{array}$ & 2 & $1.53 \%$ \\
\hline 2 & Acute on chronic cholecystitis & 3 & $2.31 \%$ \\
\hline 3 & Chronic cholecystitis & 104 & $80 \%$ \\
\hline 4 & $\begin{array}{l}\text { Chronic cholecystitis with } \\
\text { focal giant cell reaction }\end{array}$ & 1 & $0.77 \%$ \\
\hline 5 & $\begin{array}{l}\text { Xanthogranulomatous } \\
\text { cholecystitis }\end{array}$ & 3 & $2.31 \%$ \\
\hline 6 & $\begin{array}{l}\text { Chronic cholecystitis with } \\
\text { intestinal metaplasia }\end{array}$ & 3 & $2.31 \%$ \\
\hline 7 & Cholesterosis & 8 & $6.15 \%$ \\
\hline 8 & Adenomatous hyperplasia & 3 & $2.31 \%$ \\
\hline 9 & GBC & 3 & $2.31 \%$ \\
\hline 10 & Total & 130 & $100 \%$ \\
\hline
\end{tabular}

Abbreviation: GBC, gallbladder cancer.
Table 5 Distribution of gallstones among patients visiting our hospital with gallstone diseases

\begin{tabular}{|l|l|l|l|}
\hline Sr. no. & Type of stone & No. of patients & Percentage \\
\hline 1 & Cholesterol & 12 & $10.43 \%$ \\
\hline 2 & Pigment & 8 & $6.96 \%$ \\
\hline 3 & Mixed & 95 & $82.61 \%$ \\
\hline 4 & Total & 115 & $100 \%$ \\
\hline
\end{tabular}

more than 0.85 , and these findings are statistically significant (-Table 6).

\section{Distribution of Gall Stones According to Age Group Range}

The most common age range for all types of stones was 31 to 40 years, followed by 41 to 50 years ( - Table 7 ).

\section{Biochemical Profile of Cholecystitis Patients}

Investigation in almost all patients with gallstone diseases visiting our hospital were within the normal range (-Table 8).

\section{Discussion}

Gallstone disease is a menace across the northern belt of India. They constitute a major part of patients coming to the outdoor patient department, and more than 50 percent of operations are occupied by patients afflicted with gallstone diseases or diseases related to it. Gallstones have an incidence of 10 to $20 \%$ worldwide. The prevalence of gallstone varies widely in different parts of world as well as various ethnic groups, like 0 to $10 \%$ in Africa and up to 60 to $70 \%$ in certain populations such as Prima Indians; this likely reflects combined differences in environmental, dietary, and genetic factors. ${ }^{14}$ Even different studies from India showed different prevalence among different geographical areas and different ethnic groups (north Indians more than south Indians). We performed an epidemiological study at our rural tertiary care center to evaluate clinicopathological and biochemical profiles of patients with symptomatic cholecystitis.

Right hypochondriac pain (79.23\%) is the most common presenting complaint of patients with symptomatic gallstone diseases. Other complaints are dyspepsia, nausea/vomiting, fever, and jaundice. Our result is in accordance with the study by Srivastava et al..$^{15}$ Dyspepsia is defined as upper abdominal or retrosternal pain or discomfort, heart burn or other symptoms considered to be referrable to the proximal alimentary tract, whereas biliary colic was defined as pain in the epigastrium or right hypochondrium, which may have radiated to the right interscapular region and did last for more than 1 hour. ${ }^{16}$

Earlier gallbladder was considered a disease of females in their 40s, but now it is seen increasingly among younger populations as well. Maximum number of patients (31.85\%) presenting to our hospital lie within 31 to 40 years of age. Similar results were seen in studies conducted by Kala et al in 2018 and EzhilArasi et al in 2015.17,18 Our study is not in accordance with Dhamnetiya et al 2020 study which still considers 41 to 50 years as the common age range. ${ }^{19}$ 
Table 6 Distribution of gallstone according to waist-to-hip ratio

\begin{tabular}{|l|l|l|l|l|}
\hline Sr. no. & Type of stone & Waist/hip ratio $<\mathbf{0 . 8 5}$ & Waist/hip ratio $>\mathbf{0 . 8 5}$ & $\mathbf{p}$-value $(\mathbf{0 . 0 5}$ significance level) \\
\hline 1 & Cholesterol Stone & 4 & 8 & 0.135 \\
\hline 2 & Pigment Stone & 0 & 8 & \\
\hline 3 & Mixed Stone & 14 & 70 & 0.92 \\
\hline
\end{tabular}

Table 7 Type of stones distribution according to age range

\begin{tabular}{|l|l|l|l|l|l|l|}
\hline Sr. no. & Stone type & $(\mathbf{2 0 - 3 0 )}$ years & $(\mathbf{3 1 - 4 0 )}$ years & $(\mathbf{4 1 - 5 0 )}$ years & $(\mathbf{5 1 - 6 0 )}$ years & $>60$ years \\
\hline 1 & Cholesterol stone & 2 & 5 & 3 & 0 & 2 \\
\hline 2 & Pigment stone & 2 & 3 & 0 & 2 & 1 \\
\hline 3 & Mixed stone & 16 & 33 & 20 & 17 & 9 \\
\hline
\end{tabular}

Table 8 Biochemical profile of patients with gallstone diseases

\begin{tabular}{|l|l|l|l|}
\hline Sr. no. & Biochemical investigation & Mean \pm SD & Margin of error (at 95\% significance level) \\
\hline 1 & S. cholesterol & $190.4 \pm 50.94$ & $190.4 \pm 12.89$ \\
\hline 2 & S. triglycerides & $126.24 \pm 61.39$ & $126.24 \pm 12.69$ \\
\hline 3 & S. HDL & $42.05 \pm 13.93$ & $42.07 \pm 2.98$ \\
\hline 4 & S. LDL & $120.33 \pm 46.25$ & $120.33 \pm 12.69$ \\
\hline 5 & S. bilirubin & $0.59 \pm 0.22$ & $0.59 \pm 0.04$ \\
\hline 6 & S. SGOT & $30.44 \pm 21.56$ & $30.44 \pm 3.99$ \\
\hline 7 & S. SGPT & $45.76 \pm 36.34$ & $45.76 \pm 6.73$ \\
\hline 8 & S. total protein & $7.34 \pm 0.65$ & $7.34 \pm 0.16$ \\
\hline
\end{tabular}

Abbreviations: HDL, high-density lipoprotein; LDL, low-density lipoprotein; SGOT, serum glutamic oxaloacetic transaminase; SGPT, serum glutamic pyruvic transaminase.

As much as $89.23 \%$ patients are females and $10.76 \%$ are male. This follows the same gender distribution as seen in literature. Gallbladder stone diseases are considered predominantly diseases of females. Gender distribution is attributable to sex hormones. Estrogen increases biliary cholesterol secretion, causing cholesterol supersaturation of bile. Similarly, hormonal replacement therapy in postmenopausal women is found to be associated with increased risk of gallstone diseases. ${ }^{20}$

As much as $80 \%$ of patients after cholecystectomy, on histopathological examination, showed chronic cholecystitis. Three patients, that is $2.31 \%$, had gallbladder cancer. Other histopathological findings are cholesterosis (6.15\%), adenomatous hyperplasia chronic cholecystitis with intestinal metaplasia, xanthogranulomatous cholecystitis, chronic cholecystitis with focal giant cell reaction, acute or chronic cholecystitis, and chronic cholecystitis with hyalinization and calcification in wall.

The most common gallstone is mixed stones (82.61\%), followed by cholesterol stone (10.43\%) and pigment stones (6.96\%). This is in concordance with studies conducted by Karlatti et al in 2016 and Mohan et al in 2005, which also found mixed stones in $81.12 \%$ and $62.3 \%$ patients, respectively. ${ }^{21,22}$ Our study is not in accordance with studies of Tandon et al in 2000 and Kala et al in 2018, which had found cholesterol stone to be the most common in patients with cholelithiasis among the north Indian population..$^{8,17}$ All types of stones were common in those between 31 to 40 years of age.

Waist-to-hip ratio is better predictor of gallstone diseases than body mass index (BMI), as it represents a measure of central adiposity. ${ }^{23}$ It is further submitted that all types of stones are found in maximum number in patients having waist-to-hip ratio more than 0.85 , and this association is statistically significant.

Literature has shown insignificant difference in the level of serum cholesterol in patients with gallstones as compared with controls. A similar trend is observed in our study. All biochemical markers, including liver function test and lipid profile, were within normal range.

\section{Conclusion}

Our study concluded that gallstones were more common in females belonging to the younger population (31-40 years), with right hypochondriac pain as presenting complaints. The most common histopathology was chronic cholecystitis with mixed types of stones, which are associated with increased waist-to-hip ratio. All biochemical markers are within normal range.

The increasing use of various modalities like ultrasonography, and recent recognition of metabolic syndromes and their links to gallstone formation, emphasize the expectation of rise in the frequency of cholesterol cholelithiasis. Our study focused only on patients visiting hospitals, and exact prevalence of gallstone in society is not known. Further studies are advocated at community level to determine exact prevalence and risk factors for gall stone formation.

Conflict of Interest

None declared. 


\section{References}

1 Plant JC, Percy I, Bates T. Gastard J, de Nercy YH. Incidence of gallbladder disease in Canada, England, and France. Lancet 1973;2(7823):249-251

2 Bateson MC. Gallstones and cholecystectomy in modern Britain. Postgrad Med J 2000;76(901):700-703

3 American Gastroenterological Association, The Burden of Gastrointestinal Diseases. Bethesda, MD: The American Gastroenterological Association; 2001

4 Aerts R, Penninckx F. The burden of gallstone disease in Europe. Aliment Pharmacol Ther 2003;18(Suppl 3) :49-53

5 Kang J-Y, Ellis C, Majeed A, et al. Gallstones-an increasing problem: a study of hospital admissions in England between 1989/1990 and 1999/2000. Aliment Pharmacol Ther 2003;17(4):561-569

6 Khuroo MS, Mahajan R, Zargar SA, Javid G, Sapru S. Prevalence of biliary tract disease in India: a sonographic study in adult population in Kashmir. Gut 1989;30(2):201-205

7 Malhotra SL. Epidemiological study of cholelithiasis among railroad workers in India with special reference to causation. Gut 1968;9(3):290-295

8 Tandon RK. Prevalence and type of biliary stones in India. World J Gastroenterol 2000;6(Suppl 3) :4-5

9 Tandon RK, Thakur VS, Basak AK, Lal K, Jayanthi V, Nijhawan S. Pigment gallstones predominate in South India. Indian J Gastroenterol 1994;13(Suppl 1):81(A-E6)1

10 Sachdeva S, Khan Z, Ansari MA, Khalique N, Anees A. Lifestyle and gallstone disease: scope for primary prevention. Indian J Community Med 2011;36(4):263-267

11 Zamani F, Sohrabi M, Alipour A, et al. Prevalence and risk factors of cholelithiasis in Amol city, northern Iran: a population based study. Arch Iran Med 2014;17(11):750-754

12 Bilal M, Haseeb A, Saad M, et al. The prevalence and risk factors of gallstone among adults in Karachi, south Pakistan: A population-based study. Glob J Health Sci 2016;9:106
13 Shaffer EA. Epidemiology and risk factors for gallstone disease: has the paradigm changed in the 21st century? Curr Gastroenterol Rep 2005;7(2):132-140

14 Shaffer EA.Gallstone disease: epidemiology of gallbladder stone disease. Best Pract Res Clin Gastroenterol 2006;20(6):981-996

15 Srivastav AC, Srivastava M, Paswan R. Spectrum of clinico-pathological presentations of gall bladder diseases in eastern UP. International Journal of Contemporary Medicine Surgery and Radiology. 2019;4(1):A18-A23

16 Colin Jones DG. Management of dyspepsia: report of a working party. Lancet 1988;1(8585):576-579

17 Kala S, et al. A prospective study comparing the clinicobiochemical profile in obese and non-obese subjects with gall stone disease. Int J Recent Sci Res 2018;9(4):26330-26334

18 EzhilArasi N, Aruna L, Basheer Bushra A, Sreedhar VV. Clinicopathological study of chronic cholecystitis with chemical analysis of Gall Stones. International Jurnl Research Health Sciences 2015;3(4):435-442

19 Dhamnetiya D, Goel MK, Dhiman B, Pathania OP. Gallstone disease and its correlates among patients attending teaching hospital of North India. J Family Med Prim Care 2019;8(1):189-193

20 Novacek G. Gender and gallstone disease. Wien Med Wochenschr 2006;156(19-20):527-533

21 Karlatti SS, Kumar GR. Incidence of various types of gallstones in patients of cholelithiasis in Belgavi. Int J Sci Stud 2016; $4(7): 21-23$

22 Mohan H, Punia RPS, Dhawan SB, Ahal S, Sekhon MS. Morphological spectrum of gallstone disease in 1100 cholecystectomies in North India. Indian J Surg 2005; 67:140-142

23 Malik P, Singla D, Garg MK, Sangwan M. Association of body mass index and waist to hip ratio with gallstone disease in patients visiting rural tertiary care center in north India. Surg Innov 2021;28(1):48-52 